\title{
Nick Sousanis, Unflattening
}

\author{
Review by Alex Winninghoff
}

Nick Sousanis. Unflattening. Harvard Press, 2015.

As a scholar and artist looking to merge artistry with educational inquiry and theory, I recently revisited Sousanis' (2015) much acclaimed Unflattening after reading a selection of his work (Sousanis, 2018) in a new edited book on Arts-Based Research in Education (Cahnmann-Taylor, 2018a). I believe more scholars, novice and experienced alike, may find inspiration by Sousanis work as it poignantly illustrates "how a rigorous practice of inquiry in and through the arts can illuminate issues of education" (Cahnmann-Taylor \& Siegesmund, 2018b). Still relevant three years after publication, Sousanis' work illustrates an important argument against the presumed hierarchy of text over images. As increasing numbers of journals and publications argue for arts-based research, I found it compelling to return to Sousanis work and review it as a unique showcase of what can be visually accomplished in a dissertation, an academic text, and with educational theory.

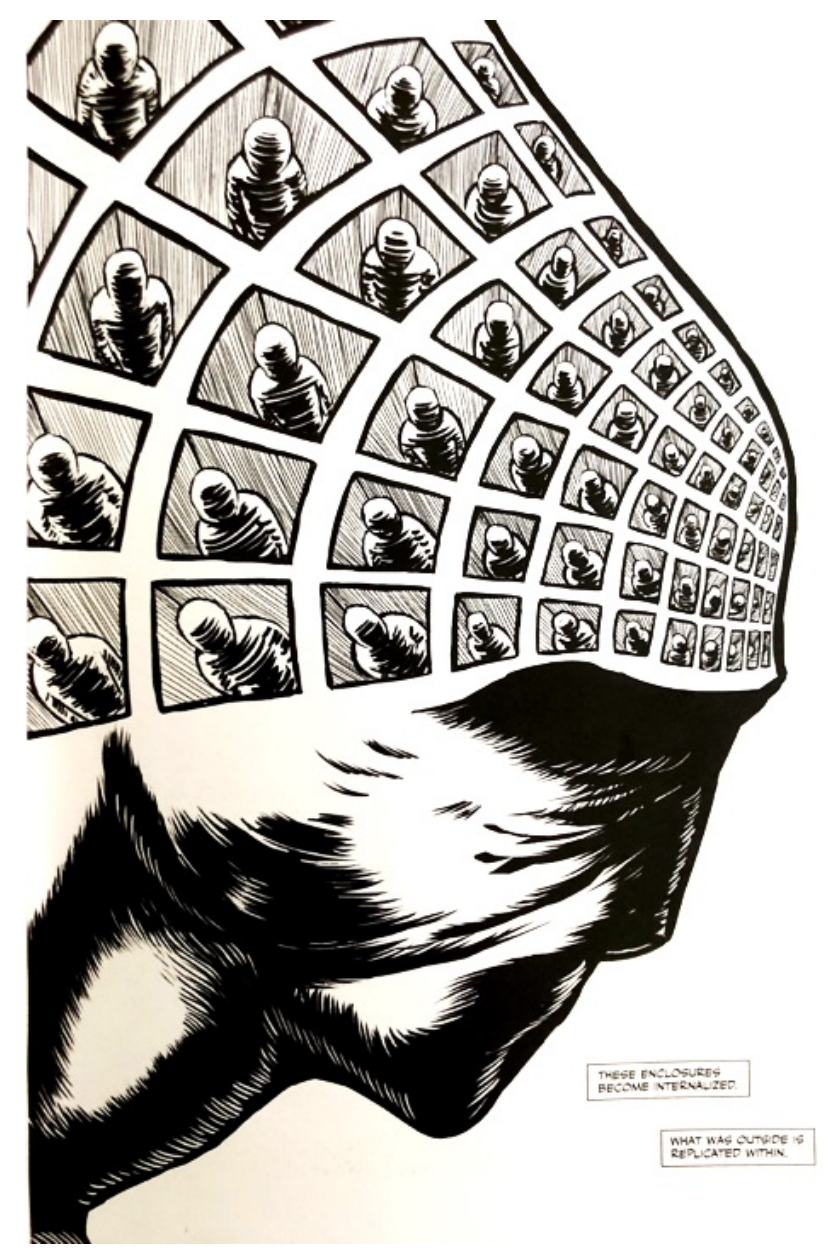

\section{Multiplicities of worlds inside us}

Communications of depth and multidimensionality permeate Unflattening, and this is developed through motifs of microcosms and devices which hold conceptual likeness. We find this first in chapter one, Flatness, where we see lifeless, dormant human figures who are being mass produced--taken down a maze of conveyor belts and through a factory where they are shaped, programed, and reduced to units of data. Each one is placed within an enclosure, and we see them as they come to be internalized within the mind of a larger being who replicates their form. Like them, he is seemingly lifeless, and his perspective is flat--limited by the presuppositions formed by his limited experience of reality. His thinking is structured, produced, and reproduced by his perceptions of the world.

The imagery communicates a narrowing and reductive epistemology--one that can only extract data from the world it is within. This is juxtaposed against Da Vinci's Vitruvian Man, an archetypal figure who "once attempted to define the universe through its own proportions, and saw within itself a microcosm of the grander sphere" (Sousanis, p. 14). This outward movement from the self to a grander sphere expresses orientations toward expansive thinking, and establishes relations and tensions between interiority and exteriority. Sousanis draws them out further in even repetitions, moving from themes of confinement to freedom, "...boxes within boxes" (p. 6) "circles within circles" (p. 33) "moments nested within moments" (p. 66) "stories within stories" (p. 95) and "depths within 
depths...dimensions curled up within us" (p. 96) He furthers these microcosmic themes through images of mathematical fractals, nesting dolls, and a multiplicity of worlds retreating infinitely within a human figure.

The multidimensionality produced by this nested self-reflexivity is furthered by the structure of Unflattening, and is created through the Interlude chapter which provides us a parallel narrative between Unflattening and Edwin Abbott's Flatlanders: A Romance of Many Dimensions. This story within the story can be understood as its mise en abyme--a literary and aesthetic device that means 'placed in the abyss,' and which conceptually parallels microcosms.

The mise en abyme of Flatlanders operates as a concentrated miniature to Unflattening. It is summarized in the Interlude chapter, and then referenced throughout to reorient the reader to its thematic parallels. It begins as a sphere from another dimension visits the protagonist, A. Square, and literally unflattens his geometric form from his one-dimensional world. The sphere and A. Square embark on a journey where they explore the depths of many dimensions through to "the abyss of no dimensions" (p. 87). Ultimately, A. Square returns home where he spends "his days trying to convince his countrymen to escape the confines of limited dimensionality" (p. 23). By establishing the mise en abyme through the one-dimensional world of 'Flatlanders' we recognize the protagonist's, A. Square's journey as parallel to that of the two-dimensional figure of Unflattening. If we follow the mise en abyme further and scope out to imagine Unflattening as the story within our own stories, we can imagine that there are potentials and horizons beyond our limited sights.

\section{"The importance of seeing double...": Parallax}

You who are blessed with shade as well as light, you who are gifted with two eyes, endowed with a knowledge of perspective and charmed with the enjoyment of various colors, you who can actually see an angle, and contemplate the complete circumference of a circle in the happy region of the three dimensions - how shall I make clear to you the extreme difficulty which we in Flatland experience in recognizing one another's configurations? (Abbott, 1899, p. 32).

The act of conceptually scoping within and without is similarly enacted as the reader oscillates between images and text, and just as clear delineations between interiority and exteriority come to be blurred through narratives of self-replication, the lines between words and images similarly diffuse. Rather than operating separately, they create what David Lewis calls an "image-text interaction, a 'double orientation' a 'looking in more than one direction at the same time" (Sousanis, p. 64) which, for Sousanis, gives us access to perception and thought that is both "tree-like and rhizomatic in one form..." (p. 62). This double orientation is described by Sousanis through the concept of parallax. In chapter three, The Importance of Seeing Double and Then Some. He demonstrates this concept of parallax by showing us how an object can seem displaced when we alternately close one eye and view it only through a singular vantage point. When we open both, we find that neither view has greater truth, and that these combined lines of sight allow us to perceive greater depth. He expands this by describing the concept of astrological parallax, which he explains allows us to "calculate distances to the stars" and "[reveals] the vast depths of space" (Sousanis, p. 31).

\section{"....and then some": Polymaths}

Double vision expands to multiple vantage points in Unflattening, partly through the vast range of thinkers Sousanis draws from, but also through the vast range within those thinkers--many of whom are polymaths whose multi and trans-disciplinary pursuits, blend logics and poetics in manners that ultimately engendered new ways of seeing.

Some of these thinkers include Eratosthenes, whose careful observations of light and shadow across time and distance allowed him to "calculate the circumference of the earth with great accuracy" (Sousanis, p. 32). He draws on Copernicus who spoke broadly across languages and disciplines, and who, "[displaced] the earth from the center and [set] it spinning...unwittingly [sparking] a revolution....and a sun-centered outlook would fuel further 


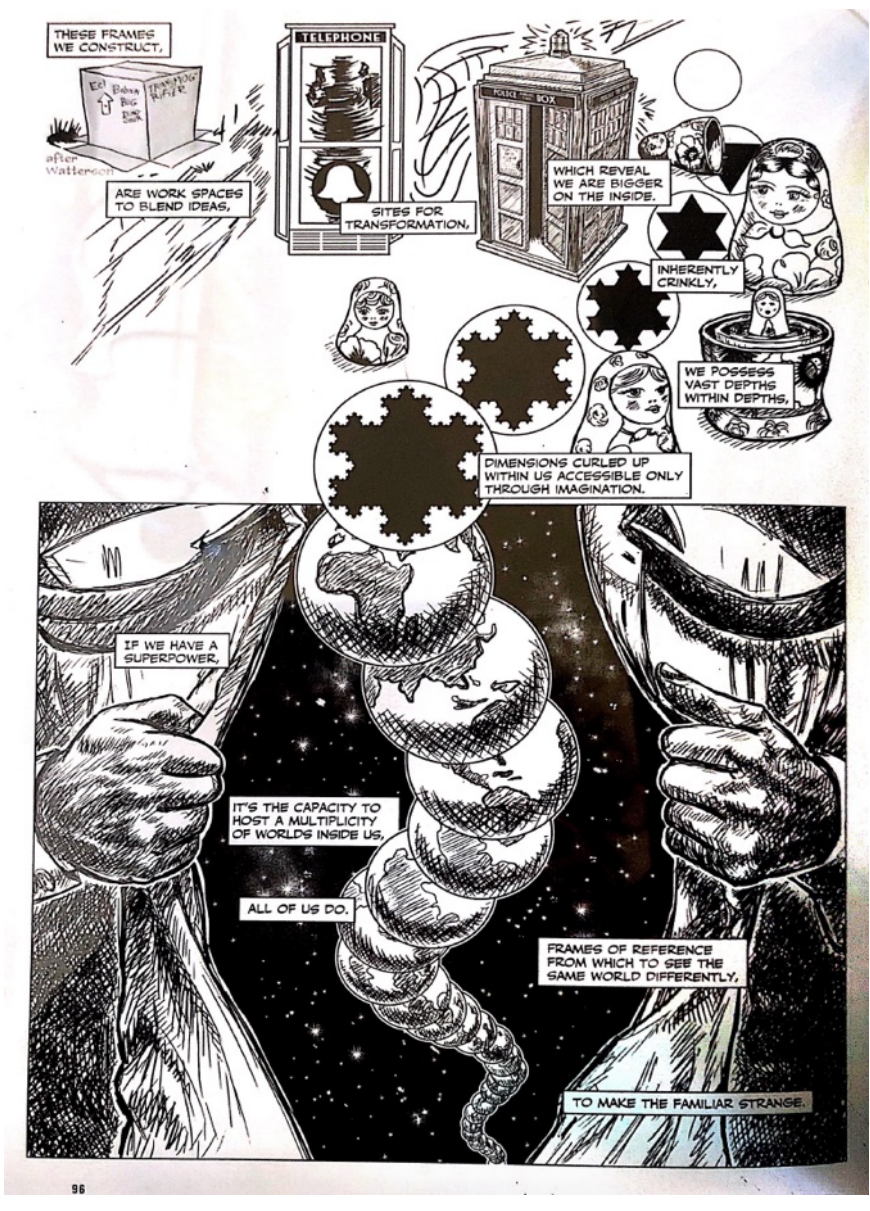

revolutions" (Sousanis, p. 33). Da Vinci, whose artistic and mathematical mind conceptualized the human as a microcosm of the universe, deepened his perceptions through studies of the natural world as a botanist to the cosmos as an astronomer. Just as Sousanis describes the restrictions that occur as we think in "delineating provinces of exclusion," Francis Bacon, similarly sought expansive thought declaring "all knowledge as his province" (Spedding, Ellis, and Heath, 1870, VIII, 109).

Bertrand Russell, a famous polymath, contributed significantly across disciplines, and was recognized as a defining figure in the logics of analytic philosophy. Among his vast ranging pursuits, he reached expansively and achieved a definition of mathematical infinity (Emmett, 1957, p. 252), and inward to connect the self to a grander sphere through love, which he described as "a mystic miniature" of the heavens (Russell, 1956, Prologue). Russell believed contradictions to be intrinsic to any area of study, and that contrasting perceptions ultimately served to enrich the mind.

Among these thinkers, theme of scaling within and without to understand repetitions and multidimensionality are continuous threads. This is perhaps best exemplified by Sousanis reference to Benoit Mandelbrot, developer of fractal mathematics, who brought shape, complexity, and recognitions of infinite self-replicating patterns of the natural world into intelligibility. This, he believed, could help "people 'see the same world differently"' (Mandelbrot/Sousanis, p. 44).

Multiplicity is also communicated through reference to James Joyce's Ulysses, which is notorious for its polyvocal narrative that Sousanis recognizes as a "literary parallax" (Sousanis, p. 45). It is also created through Italo Calvino, also known for his layered narratives, and who, like Sousanis used images and text to communicate complexity through layered signification. Calvino describes his work as a joining of "spontaneous generation of images to the intentionality of logical thought" which creates potentials for images to, "[show] up unexpectedly to decide situations that neither the surmises of thought nor the resources of language would be able to resolve" (1988, pp. 110-111).

These thematic similarities among their work extends further to Sousanis himself, whose philosophical work is informed by his background as an accomplished mathematician, writer, and artist. Through a mirroring between their philosophies and intellectual engagements, another parallelism develops as a subtext to Unflattening--one which highlights a lineage of thinkers whose work gave entry into "...multiple ways of seeing [that allowed] access to multidimensional sight" and as new potentials for thought emerge, "existing barriers tumble and creative possibilities flourish" (Sousanis, p. 82).

Sousanis asks "what can be made visible when we work in a form that is not only about, but is also the thing itself" (pp. 58-59). For scholars of arts based research, this is a question that Sousanis effectively answers through his work. Unflattening remains a relevant exemplar for how rigorous scholarship can be achieved through creative practice, and in a manner that serves a vast range of readers by reaching beyond the confines of conventionality. 


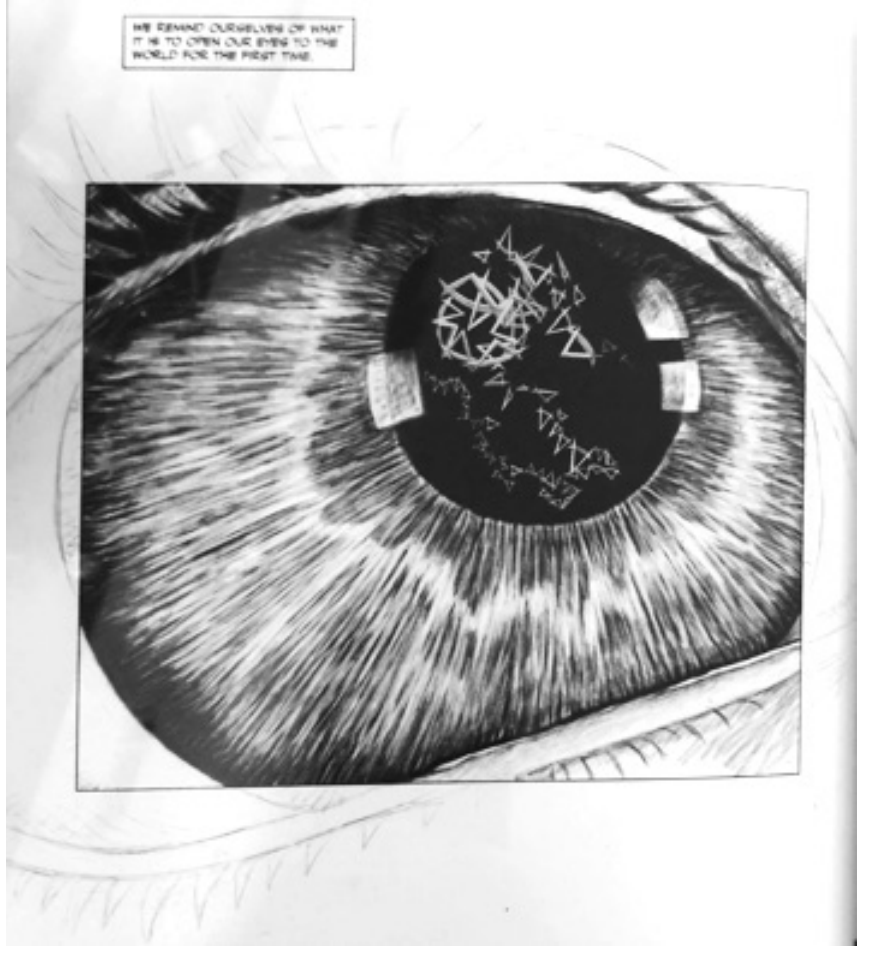

\section{References}

Abbott, E. A. (1963). Flatland: A romance of many dimensions. London: Seeley, 1884. Reprint, New York: Dover, 1952.

Cahnmann-Tayor, M. \& Siesmund R. (2018a). Artsbased research in education: Foundations for practice. New York: Routledge.

Cahnmann-Tayor, M. \& Siesmund R. (2018b). "Introduction." In M. Cahnmann-Taylor \& R. Siegesmund (Eds.) Arts-based research in education: Foundations for practice. New York: Routledge.

Deleuze, G., \& Guattari, F. (2004). A thousand plateaus: Capitalism and schizophrenia. London: Continuum.

Marcuse, H. (1964). One-Dimensional Man: Studies in the Ideology of Advanced Industrial Society 2nd ed. Boston: Beacon Press, 1991.

Russell, B. (1967). The Autobiography of Bertrand Russell. 3 vols. London: George Allen and Unwin; Boston: Little Brown and Company (Vols 1 and 2), New York: Simon and Schuster (Vol. 3).

Sousanis, N. (2015) Unflattening. Cambridge, Mass.: Harvard University Press.

Sousanis, N. (2018) Thinking in comics: An Emerging Process. In M. Cahnmann-Taylor \& R. Siegesmund (Eds.) Arts-based research in education: Foundations for practice. New York: Routledge.

\section{Cite this Essay}

Winninghoff, Alex. "Nick Sousanis, Unflattening." Rhizomes: Cultural Studies in Emerging Knowledge, no. 35, 2019, doi:10.20415/rhiz/035.r03 